\title{
VINCULAÇÃO CONSTITUCIONAL DE RECURSOS MÍNIMOS NA EDUCAÇÃO ESTADUAL DO RIO DE JANEIRO 1995-2015
}

\author{
Fábio Araujo de Souza \\ Rubens Barbosa de Camargo ${ }^{(*)}$
}

A vinculação constitucional de impostos é provavelmente o aspecto mais importante da discussão sobre o financiamento da educação estatal.

(Nicholas Davies, 2004)

\section{APRESENTAÇÃO}

O objetivo da presente pesquisa é analisar o cumprimento da aplicação do percentual de recursos mínimos para Manutenção e Desenvolvimento do Ensino (MDE) pelos governos estaduais do Rio de Janeiro, eleitos no período de 1995 a 2015. Além disso, a presente pesquisa aborda a aplicação de recursos para MDE em todos os estados brasileiros demonstrando que alguns também não cumprem o percentual mínimo determinado por sua Constituição, aliás, muitos não aplicam nem mesmo o percentual mínimo previsto na Constituição Federal de 1988 (CF/88).

Está prevista na CF/88, no seu artigo 212, a aplicação, pelos governos estaduais, de, no mínimo, 25\% da receita resultante de impostos e transferências na MDE. A Lei de Diretrizes e Bases da Educação Nacional (LDB) 9.394/1996, contudo, vai além e determina no artigo 69 que o percentual que consta na Constituição Estadual deve ser levado em consideração como mínimo aplicado em MDE. Porém, muitos governos estaduais vêm desrespeitando a interpretação da LDB, dentre eles, o governo do estado Rio de Janeiro.

O estado do Rio de Janeiro teve, em 2013, o segundo maior Produto Interno Bruto (PIB) em comparação com os demais estados. Além disso, tem uma das maiores redes de ensino do país. Porém, desde 1998, os governantes têm aplicado algo em torno de $25 \%$ da receita resultante de impostos e transferências na $\mathrm{MDE}$, ou seja, próximo do mínimo previsto na $\mathrm{CF} / 88$, adotando a interpretação de que deveriam seguir o texto da $\mathrm{CF} / 88$ e não o que determina a Constituição Estadual que prevê a aplicação de, no mínimo, 35\%.

O Poder Judiciário, através do Supremo Tribunal Federal (STF), concedeu duas liminares (1993 e 2008) para que o governo estadual cumprisse o percentual da CF/88 e, portanto, não fosse

\footnotetext{
${ }^{(*)}$ Fábio Araujo de Souza. Pedagogo e Mestre em Educação pela Universidade do Estado do Rio de Janeiro (UERJ), Doutor em Educação pela Universidade de São Paulo (USP) e Docente da Universidade Federal de Goiás (UFG) Regional Catalão.

Rubens Barbosa de Camargo. Doutor em Educação. Professor da Universidade de São Paulo (USP). E-mail: rubensbc $\underline{\text { usp.br }}$
} 
obrigado a cumprir o percentual da Constituição Estadual. Depois de mais de vinte anos do primeiro pedido de inconstitucionalidade do artigo da Constituição Estadual que determinava a vinculação de, no mínimo, $35 \%$ da receita de impostos e transferências para MDE, o STF decidiu que a vinculação prevista era inconstitucional.

Este artigo está dividido em quatro seções. A primeira discute algumas questões acerca do federalismo e dos seus efeitos na república brasileira e na educação; a segunda esclarece algumas questões referentes à vinculação constitucional de impostos para a educação no Brasil e no estado do Rio de Janeiro; a terceira aborda especificamente a questão da vinculação de recursos mínimos nos governos eleitos do estado do Rio de Janeiro no período de 1995 a 2015; e a última traz as considerações finais da pesquisa.

A pesquisa é quali-quantitativa que busca desde a análise do referencial teórico até a coleta e sistematização de dados dos recursos da educação nos governos fluminenses no período pesquisado. Foi realizada pesquisa bibliográfica baseada, basicamente, por autores da área das políticas em educação, sobretudo, do financiamento público da educação, além de coleta e sistematização de dados referentes ao financiamento da educação dos governos estaduais. Buscou-se, com isso, demonstrar as fragilidades do financiamento da educação no estado do Rio de Janeiro, acima de tudo, pela aplicação do percentual de recursos mínimos estabelecido na Constituição Estadual.

A insistente crise na educação fluminense deriva, também, da irresponsabilidade dos governos em deixarem de aplicar o percentual mínimo de recursos previsto na Constituição Estadual, embora, esse não seja o único entrave em relação ao financiamento da educação fluminense ele tem efeitos negativos consideráveis para a qualidade da educação estadual. Portanto, esta pesquisa justifica-se pelo fato de apresentar este problema e discuti-lo com dados consistentes e análises pertinentes acerca da vinculação do percentual de recursos mínimos para educação estadual, e também, da judicialização que se deu em torno desta questão.

\section{O FEDERALISMO E A EDUCAÇÃO NO ESTADO BRASILEIRO: AUTONOMIA E COOPERAÇÃO ENTRE OS ENTES?}

A CF/88 sinalizou para um novo pacto federativo em que a lógica da política está estruturada na autonomia e no regime de cooperação entre União, estados, Distrito Federal e municípios, definido no artigo 23. Porém, essa lógica somente logrará êxito se ao federalismo jurídico-político corresponder um federalismo fiscal e tributário. Desta forma, o almejado equilíbrio do desenvolvimento e do bem-estar, em âmbito nacional estará, provavelmente, assegurado. 
Com relação à educação e sua função dentro da República Federativa, Dourado (2013, p. 766) destaca a necessidade de se repensar o sistema tributário nacional e as condições objetivas de cada ente federado nesse processo:

\begin{abstract}
É possível deduzir desses princípios constitucionais que proporcionar os meios de acesso à educação é dever de todos os entes federados e que sua efetivação deve ser resultante da cooperação e colaboração, o que não prescinde de normas nacionais, bem como de normas subnacionais articuladas, ou seja, o exercício da autonomia deve se efetivar no horizonte tensionado pelas condicionalidades e complementaridade, o que, no caso brasileiro, implica repensar o sistema tributário nacional e as condições objetivas dos entes federados nesse processo, por meio de uma reforma tributária que deslinde novos horizontes ao processo de descentralização das políticas.
\end{abstract}

Com certeza a assimetria regional e a desigualdade social marcadamente em nosso país contribuem para que o federalismo não se estruture de forma plena. O papel da União não pode se reduzir à centralização da coordenação federativa, mas, sim, no processo de coordenação da cooperação e da colaboração entre os entes federados, baseando-se na gestão democrática e participativa.

Para Davies (2016), o federalismo através da autonomia e do regime de cooperação entre União, estados, Distrito Federal e municípios está longe de ser conquistado, sobretudo pela preponderância federal na definição das políticas educacionais. $\mathrm{O}$ autor usa como exemplo a desigualdade na organização da educação pública e nas políticas educacionais, sobretudo, através da ausência de participação ativa e consciente dos estados e municípios na criação da política de Fundos (Fundo de Manutenção e Desenvolvimento do Ensino Fundamental e de Valorização do Magistério - Fundef e o Fundo de Manutenção e Desenvolvimento da Educação Básica e de Valorização dos Profissionais da Educação - Fundeb); a pouca responsabilidade da União com obrigatoriedade da oferta educação básica; a distribuição desigual dos recursos do salário-educação; dentre outros. Davies (2016, p. 118) afirma que o pacto federativo no Brasil é fíctício, pois "a instância federal tem decidido questões que afetam os entes subnacionais sem consultá-los e tais decisões muitas vezes significam mais responsabilidades para eles porém sem os recursos financeiros necessários".

Por fim, como comprovado na pesquisa de Davies (2016, p. 124), os estados brasileiros estão diminuindo, significativamente, suas matrículas na educação básica, sobretudo no Ensino Fundamental, através da transferência para as prefeituras, "contrariando a CF e também a LDB, que definem o Ensino Fundamental como responsabilidade conjunta de Estados e Municípios".

No que se refere ao financiamento da educação, o governo federal é o ente que tem a maior arrecadação e o que menos contribui, isto é, apenas $18 \%$ da receita resultante de impostos. Por outro 
lado, cabe ressaltar que o Rio de Janeiro que dispõe de uma volumosa arrecadação, não tem aplicado um percentual de impostos, além do mínimo previsto na $\mathrm{CF} / 88$, desde 1998 , mesmo sendo determinado em sua Constituição o percentual mínimo de $35 \%$.

\section{A VINCULAÇÃO LEGAL DE RECURSOS PARA A MDE NO BRASIL}

A vinculação de percentual de impostos para financiar a educação é antiga, remete ao período colonial e foi materializada através do subsídio literário. Em 1934, foi promulgada a terceira Constituição do Brasil, a primeira que previa a vinculação de impostos para o ensino. O seu artigo 156 determinava que a aplicação seria nunca menos de $10 \%$ da renda resultante de impostos da União e dos municípios e, no mínimo, 20\% dos estados e do Distrito Federal.

Contudo, essa vinculação não aparece no texto da Constituição de 1937 - conhecida como Polaca, por ter sido inspirada no modelo semifascista polonês -, que era extremamente autoritária e concedia ao governo poderes praticamente ilimitados. A vinculação aparece novamente na Constituição de 1946, artigo 169, ao determinar que a União aplicaria nunca menos de $10 \%$, e os estados, o Distrito Federal e os municípios, nunca menos de $20 \%$ da renda resultante dos impostos na MDE.

Novamente, a vinculação de impostos para o ensino não aparece no texto da Constituição de 1967, semioutorgada em plena Ditadura Civil-Militar. Na reforma Constitucional outorgada em 1969 (Emenda Constitucional 1/69), a vinculação retorna, porém, apenas para o ensino primário dos municípios. Com a Emenda Constitucional 24 de 1983 proposta pelo então senador João Calmon, a vinculação volta a prevalecer plenamente. Segundo a emenda, a União aplicaria 13\%, no mínimo, da receita de impostos na MDE e, pelo menos $25 \%$ da receita dos estados, do Distrito Federal e dos municípios (VELLOSO, 1990).

Com o fim da Ditadura Civil-Militar e com a redemocratização, foi realizada uma nova constituinte que elaborou a CF/88. Para o financiamento da educação, a CF/88 prevê no artigo 212 que a União aplicará, anualmente, nunca menos de 18\%, e os estados, o Distrito Federal e os municípios, 25\%, no mínimo, da receita resultante de impostos, compreendida a proveniente de transferências, na MDE.

Contudo, o descumprimento do percentual mínimo legalmente e constitucionalmente previsto para ser aplicado na MDE tem sido recorrente no Brasil por vários entes federados. $\mathrm{O}$ pesquisador Jaques Velloso (1990) aponta em sua pesquisa que a União descumpriu a aplicação de 13\% da receita de impostos na MDE no período de 1986 a 1988. Davies (2004) também aponta em sua pesquisa que os governos estadual e municipais do Rio de Janeiro descumpriram a aplicação do 
percentual mínimo em MDE. No estado de São Paulo, o pesquisador Callegari (1997) denunciou o governo estadual que deixou de aplicar R\$ 5,2 bilhões em MDE de 1995 a 1998.

Outro caso de descumprimento de aplicação do percentual mínimo é do estado de Goiás, que afirmou ter aplicado 25,12\% da receita resultante de impostos e transferências na MDE, em 2015. Porém, o Tribunal de Contas do Estado de Goiás (TCE-GO) retirou das despesas com MDE R \$ 24 milhões que o governo aplicou em merenda escolar, o que é proibido pela LDB, segundo o artigo 71, inciso VI. Com a retirada dessa despesa, o percentual caiu para 24,95\%. Mesmo com o descumprimento do percentual mínimo previsto pela $\mathrm{CF} / 88$, as contas do governador Marconi Perillo receberam parecer favorável do TCE-GO. Segundo a CF/88, artigo 34, inciso VII, está prevista a intervenção da União no Estado caso não seja aplicado o percentual mínimo em MDE, mas a medida não foi adotada nos casos aqui citados, o que demonstra a conivência da União com essa ilegalidade cometida por vários estados.

A LDB aprovada em 1996 prevê no artigo 69 que a União aplicará, anualmente, nunca menos de $18 \%$, e os estados, o Distrito Federal e os municípios, 25\%, ou o que consta nas respectivas Constituições ou Leis Orgânicas, da receita resultante de impostos, e das transferências constitucionais, na MDE. A Constituição Estadual do Rio de Janeiro prevê a aplicação de, no mínimo, 35\%. No entanto, desde 1998, os governos estaduais não têm aplicado o percentual previsto na Constituição Estadual sob o argumento de que devem seguir o percentual mínimo previsto na Constituição Federal.

Segundo Davies (1997, p. 56):

Uma outra novidade introduzida pelo Art. 69 em relação à CF foi a de o percentual mínimo válido ser, no caso de Estados, Distrito Federal e Municípios, o estabelecido nas suas respectivas Constituições Estaduais e Leis Orgânicas, não o da CF (25\%), como espertamente interpretado por governos estaduais e municipais e aceito por alguns Tribunais de Contas, como o do Estado do Rio de Janeiro.

Com relação à mudança na $\mathrm{LDB}$, do texto que determina a vinculação de impostos e transferências legais e constitucionais, no que se refere a considerar o percentual mínimo que consta nas Constituições Estaduais e nas Leis Orgânicas, Castro (2010, p. 173) afirma que a LDB corrigiu a CF/88:

\footnotetext{
Além disso, realizou uma correção importante na $\mathrm{CF} / 88$ no que diz respeito ao percentual mínimo da receita de impostos a ser aplicado na educação em cada localidade. Segundo a LDB, uma vez respeitado o índice mínimo nacional, os percentuais podem variar regionalmente de acordo com o que conste nas respectivas Constituições ou Leis Orgânicas dos estados, DF e municípios, reconhecendo a possibilidade de esses entes federados ampliarem o valor do índice mínimo fixado na $\mathrm{CF} / 88$.
} 
Contudo, cabe destacar que o termo "correção" utilizado pelo autor supramencionado não é o mais adequado, uma vez que para corrigir a CF/88 somente uma emenda constitucional poderia fazê-lo, pois uma lei federal não tem essa prerrogativa.

O cumprimento da vinculação legal de impostos e transferências pelos entes federados é um enorme desafio, sobretudo quando o percentual mínimo definido pela CF/88 é ampliado pela Constituição Estadual (no caso dos governos estaduais) e pela Lei Orgânica (no caso do governo do Distrito Federal e dos municípios). Ao promulgar sua Constituição Estadual ou Lei Orgânica, alguns governos ampliaram o percentual mínimo de receita resultante de impostos e transferências na MDE previsto na CF/88. Segundo Travincas (2016, p. 96):

O dever do Estado para com a educação de que fala o artigo 205 da CF é, assim, um dever de satisfação progressiva, sendo o mínimo apenas a fatia inegociável de sua promoção - o que não importa dizer que seja exclusivamente esta a parcela esperada.

A CF/88 determina que os estados, o Distrito Federal e os municípios devem aplicar, no mínimo, $25 \%$ da receita de impostos e transferências na MDE. Contudo, se por viabilidade financeira ou por quaisquer outros motivos o Poder Legislativo (no processo de elaboração da Constituição Estadual ou Lei Orgânica) ou o Poder Executivo entender que o ente pode aplicar um percentual acima do previsto na $\mathrm{CF} / 88$, isso poderá ocorrer mediante determinação da Constituição Estadual ou na Lei Orgânica.

Fato curioso é que, mesmo estando previsto um percentual acima do determinado pela CF/88 em algumas Constituições Estaduais e Leis Orgânicas, diversos governos desrespeitaram e continuam desrespeitando o percentual maior alegando que, ao promulgar a Constituição ou a Lei Orgânica, os deputados ou, no caso da Lei Orgânica, os vereadores incorreram em um erro legal ao legislar sobre uma matéria exclusiva do Poder Executivo que é o aumento de despesa. Para deixar de serem obrigados a aplicar um percentual maior que o previsto na $\mathrm{CF} / 88$, muitos governos apelaram ao Supremo Tribunal Federal (STF) e ao Tribunal de Justiça (TJ) solicitando a suspensão do percentual previsto na Constituição ou Lei Orgânica via medida liminar. Em outros casos o Poder Executivo dos governos estaduais e municipais enviaram Propostas de Emenda à Constituição Estadual ou à Lei Orgânica no sentido de reduzir o percentual.

Com relação ao Poder Legislativo estadual e distrital e seus órgãos auxiliares, os Tribunais de Contas, é possível notar que, em sua maioria, são coniventes com o descumprimento do percentual mínimo estipulado pela Constituição Estadual (governos estaduais) e pela Lei Orgânica (governo do $\mathrm{DF}$ ) e até mesmo pela $\mathrm{CF} / 88$, pois, segundo levantamento realizado nas 26 Constituições Estaduais, na Lei Orgânica do Distrito Federal e no site do Sistema de Informações 
sobre Orçamentos Públicos em Educação do Fundo Nacional de Desenvolvimento da Educação (Siope/FNDE) ${ }^{1}$, foi possível constatar que os estados do Rio Grande do Norte e de Alagoas não aplicaram o percentual mínimo previsto na Constituição Estadual e, portanto, o mínimo previsto na CF/88, já que ambas determinam a aplicação de no mínimo $25 \%$; a média do percentual aplicado pelos governos desses estados, de 2008 a 2015, foi de 24,6\% e de 23,2\%, respectivamente, conforme se demonstra na Figura 1.

Figura 1 - Comparação entre o percentual determinado pela Constituição Estadual e a média do percentual aplicado na MDE de 2008 a 2015 dos governos estaduais
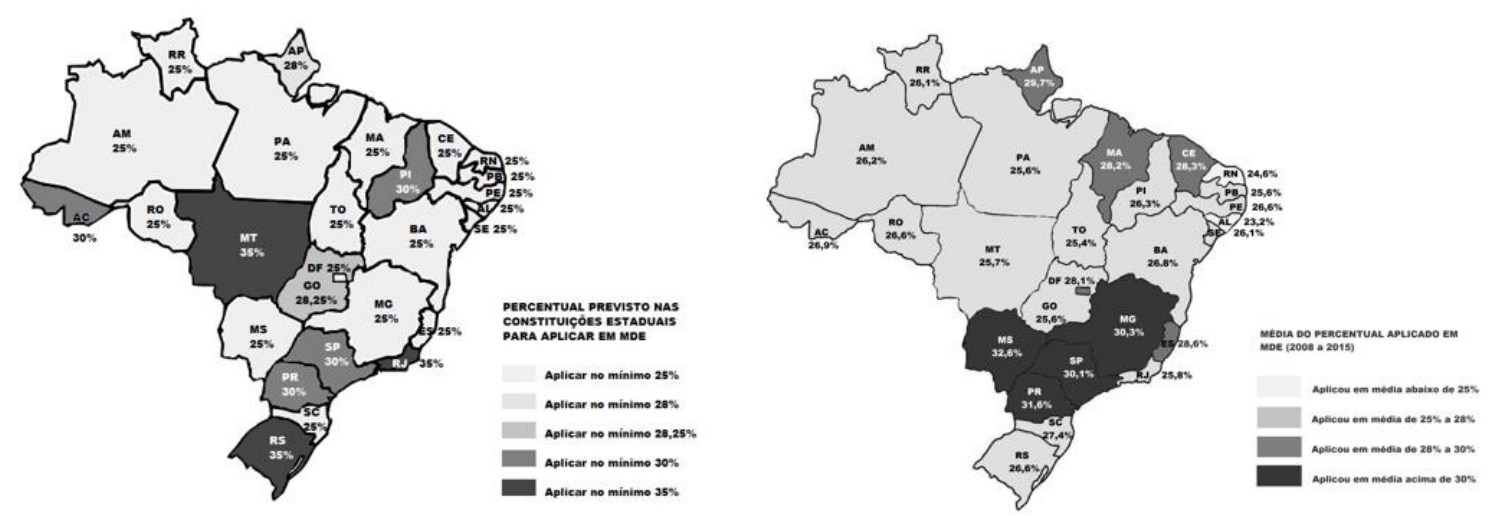

Fonte: Constituições Estaduais, Lei Orgânica do Distrito Federal e Siope/FNDE. Figura elaborada pelo autor.

A Figura 1 apresenta dois mapas: o da esquerda revela o percentual mínimo de impostos e transferências previsto na Constituição Estadual dos 26 estados e na Lei Orgânica do Distrito Federal. O mapa da direita apresenta a média do que realmente os governos estaduais e distrital afirmam ter aplicado em MDE de 2008 a 2015.

Embora a fidedignidade dos dados apresentados pelos governos estaduais e distrital ao Siope/FNDE seja questionável - pois ao compará-los com os dos Tribunais de Contas nota-se, em alguns casos, desigualdades nesses percentuais - trata-se de um banco de dados que permite o acesso a diversas informações que em muitos casos são difíceis de serem encontradas em outras fontes na sequência histórica pesquisada.

É possível observar no mapa da esquerda que em 17 estados a Constituição Estadual determina a aplicação de 25\%. No Distrito Federal, a determinação da Lei Orgânica é de que, no mínimo, 25\% seja aplicado em MDE. A Constituição do Estado do Amapá determina a aplicação de

\footnotetext{
${ }^{1}$ Sistema eletrônico, instituído para coleta, processamento, disseminação e acesso público às informações referentes aos orçamentos públicos de educação da União, dos estados, do Distrito Federal e dos municípios, operacionalizado pelo FNDE.
} 
28\%, ou seja, 3\% acima do percentual mínimo previsto na $\mathrm{CF} / 88$. A Constituição de Goiás prevê a aplicação de 28,25\%, enquanto as Constituições Estaduais do Piauí, do Acre, de São Paulo e do Paraná preveem 30\%. A figura revela, também, que apenas em três estados (Mato Grosso, Rio Grande do Sul e Rio de Janeiro) a Constituição determina o percentual mínimo de $35 \%$.

Contudo, ao comparar os dois mapas, pode-se perceber a distância do legal para o efetivamente realizado, uma vez que há diferenças entre o que é determinado legalmente pelas Constituições Estaduais e o que os governos afirmam ter sido aplicado nos últimos 8 exercícios financeiros em MDE.

Dos 17 governos estaduais cuja Constituição Estadual determina a aplicação de, no mínimo, 25\% em MDE, Mato Grosso do Sul e Minas Gerais aplicaram em média percentuais acima de 30\% e 3 governos (Espírito Santo, Ceará e Maranhão) aplicaram 28,6\%, 28,3\% e 28,2\%, respectivamente. O DF aplicou em média 28,1\%. Os governos estaduais de Santa Catarina, da Bahia, de Pernambuco, do Amazonas, de Roraima, Sergipe, Rondônia, da Paraíba, do Pará e de Tocantins aplicaram em média percentuais que variaram de $25,4 \%$ a $27,4 \%$. Os governos do Rio Grande do Norte e de Alagoas descumpriram os percentuais determinados tanto pela Constituição Estadual quanto pela $\mathrm{CF} / 88$ e aplicaram percentuais abaixo de $25 \%$.

A média aplicada em MDE dos estados em que a Constituição Estadual prevê um percentual mínimo acima do previsto na CF/88 teve variações. O Amapá cumpriu o percentual determinado em sua Constituição, aplicando em média 29,7\%. O governo estadual de Goiás descumpriu sua Constituição e aplicou em média 25,6\%. Os governos estaduais de São Paulo e do Paraná cumpriram o percentual mínimo previsto na Constituição e aplicaram em média 31,6\% e 30,1\%, respectivamente. O governo estadual do Piauí e do Acre não cumpriram o previsto em suas Constituições e aplicaram em média $26,3 \%$ e $26,9 \%$, respectivamente. Os estados do Rio Grande do Sul, Rio de Janeiro e Mato Grosso aplicaram em média percentuais bem inferiores ao determinado em suas Constituições: $26,6 \%, 25,8 \%, 25,7 \%$, respectivamente.

Tabela 1 - Receita líquida de impostos e total de despesas em MDE dos estados brasileiros de 2008 a 2015. Valores nominais $(\mathrm{R} \$)$

\begin{tabular}{cccccc}
\hline Estado & $\begin{array}{c}\text { Total da Receita Líquida de Impostos } \\
(\mathbf{2 0 0 8 - 2 0 1 5 )}\end{array}$ & $\begin{array}{c}\text { \% em MDE } \\
\mathbf{( 2 0 0 8 - 2 0 1 5 )}\end{array}$ & \multicolumn{2}{c}{$\begin{array}{c}\text { Total das despesas em MDE } \\
(\mathbf{2 0 0 8 - 2 0 1 5})\end{array}$} \\
\hline AC & $\mathrm{R} \$$ & $21.526 .248 .259,27$ & $26,9 \%$ & $\mathrm{R} \$$ & $5.724 .312 .747,46$ \\
\hline AL & $\mathrm{R} \$$ & $35.408 .196 .603,36$ & $23,2 \%$ & $\mathrm{R} \$$ & $7.810 .997 .204,12$ \\
\hline AP & $\mathrm{R} \$$ & $20.699 .236 .239,72$ & $29,7 \%$ & $\mathrm{R} \$$ & $6.092 .548 .501,15$ \\
\hline AM & $\mathrm{R} \$$ & $56.457 .511 .061,75$ & $26,2 \%$ & $\mathrm{R} \$$ & $14.465 .510 .194,73$ \\
\hline BA & $\mathrm{R} \$$ & $137.040 .790 .533,63$ & $26,8 \%$ & $\mathrm{R} \$$ & $36.160 .974 .624,51$ \\
\hline CE & $\mathrm{R} \$$ & $85.862 .498 .023,04$ & $28,3 \%$ & $\mathrm{R} \$$ & $23.591 .471 .060,83$ \\
\hline DF & $\mathrm{R} \$$ & $83.208 .091 .246,15$ & $28,1 \%$ & $\mathrm{R} \$$ & $23.825 .753 .144,81$ \\
\hline
\end{tabular}




\begin{tabular}{|c|c|c|c|c|c|}
\hline $\mathbf{E S}$ & $\mathrm{R} \$$ & $57.615 .725 .167,45$ & $28,6 \%$ & $\mathrm{R} \$$ & $16.164 .643 .742,69$ \\
\hline GO & $\mathrm{R} \$$ & $84.864 .180 .500,70$ & $25,6 \%$ & $\mathrm{R} \$$ & 21.463.597.764,58 \\
\hline MA & $\mathrm{R} \$$ & 60.233.975.512,22 & $28,2 \%$ & $\mathrm{R} \$$ & $16.621 .431 .761,23$ \\
\hline MT & $\mathrm{R} \$$ & 49.965.941.307,49 & $25,7 \%$ & $\mathrm{R} \$$ & 12.742.311.263,56 \\
\hline MS & $\mathrm{R} \$$ & $44.315 .276 .168,42$ & $32,6 \%$ & $\mathrm{R} \$$ & $14.453 .042 .611,85$ \\
\hline MG & $\mathrm{R} \$$ & $236.061 .141 .883,76$ & $30,3 \%$ & $\mathrm{R} \$$ & $72.452 .650 .804,56$ \\
\hline $\mathbf{P A}$ & $\mathrm{R} \$$ & $77.157 .446 .641,60$ & $25,6 \%$ & $\mathrm{R} \$$ & $19.306 .527 .989,87$ \\
\hline PB & $\mathrm{R} \$$ & 44.791.779.137,21 & $25,6 \%$ & $\mathrm{R} \$$ & $11.185 .464 .701,77$ \\
\hline PR & $\mathrm{R} \$$ & 142.596.474.681,35 & $31,6 \%$ & $\mathrm{R} \$$ & 45.782.299.330,47 \\
\hline PE & $\mathrm{R} \$$ & $100.584 .519 .445,76$ & $26,6 \%$ & $\mathrm{R} \$$ & 26.520.397.660,72 \\
\hline PI & $\mathrm{R} \$$ & $36.539 .609 .446,40$ & $26,3 \%$ & $\mathrm{R} \$$ & $9.381 .976 .904,02$ \\
\hline RJ & $\mathrm{R} \$$ & $217.642 .972 .872,52$ & $25,8 \%$ & $\mathrm{R} \$$ & $55.587 .240 .637,00$ \\
\hline $\mathbf{R N}$ & $\mathrm{R} \$$ & $44.210 .406 .731,95$ & $24,6 \%$ & $\mathrm{R} \$$ & $10.610 .962 .591,92$ \\
\hline $\mathbf{R S}$ & $\mathrm{R} \$$ & 157.746.519.776,11 & $26,6 \%$ & $\mathrm{R} \$$ & 43.885.907.141,46 \\
\hline RO & $\mathrm{R} \$$ & $30.418 .601 .368,89$ & $26,0 \%$ & $\mathrm{R} \$$ & 7.791.873.117,23 \\
\hline $\mathbf{R R}$ & $\mathrm{R} \$$ & $15.375 .738 .813,08$ & $26,1 \%$ & $\mathrm{R} \$$ & $4.420 .064 .431,07$ \\
\hline SC & $\mathrm{R} \$$ & $92.913 .736 .482,75$ & $27,4 \%$ & $\mathrm{R} \$$ & $25.701 .930 .283,93$ \\
\hline SP & $\mathrm{R} \$$ & 758.527.428.112,52 & $30,1 \%$ & $\mathrm{R} \$$ & $216.615 .830 .036,34$ \\
\hline SE & $\mathrm{R} \$$ & $35.310 .511 .640,28$ & $26,1 \%$ & $\mathrm{R} \$$ & 8.975.884.036,99 \\
\hline TO & $\mathrm{R} \$$ & $31.720 .133 .793,60$ & $25,4 \%$ & $\mathrm{R} \$$ & 7.936.145.058,45 \\
\hline TOTAL & $\mathbf{R} \$$ & 2.758.794.691.450,98 & & $\mathbf{R} \$$ & 765.271.749.347,32 \\
\hline
\end{tabular}

Fonte: Siope/FNDE. Tabela elaborada pelo autor.

A fragilidade do pacto federativo fica evidente analisando a receita líquida de impostos e transferências, pois é possível notar que governos estaduais, cujas receitas são menores que de outros, aplicam percentual mínimo na MDE superior a governos estaduais com receita maior. Por exemplo, no caso do governo de Roraima, que teve em média a menor receita líquida de impostos de todos os estados, aproximadamente, R \$ 15 bilhões, mas aplicou em MDE o percentual médio de 26,1\% de 2008 a 2015; enquanto o governo do Rio de Janeiro teve uma receita líquida de impostos de, aproximadamente, R 218 bilhões e aplicou 25,8\% em MDE. Mesmo levando em consideração a disparidade entre o valor aplicado na MDE dos dois governos estaduais, há que se observar que o impacto daquilo que foi aplicado relativamente em relação ao arrecadado, a priori, demonstra um maior compromisso do governo de Roraima em relação ao governo fluminense com a educação estadual.

Além disso, outros fatores contribuem para a "perda" de recursos na área da educação, tais como: o cancelamento de despesa empenhada de um exercício financeiro para o outro; as limitações das políticas fiscal e tributária; a corrupção dos recursos da educação; a contabilização inadequada de impostos e transferências para aplicar na MDE; a não contabilização das aplicações financeiras dos recursos da educação, sobretudo do Fundeb; o pagamento de despesas que não se enquadram em educação, ou até mesmo em MDE; a ausência ou o pouco controle e acompanhamento social 
dos recursos da educação; a subordinação do Poder Legislativo ao Poder Executivo; as relações patrimonialistas e clientelista entre os poderes, que, dentre outros motivos, têm dilapidado o erário dos entes federados, sobretudo, por interesses escusos entre o capital privado e a classe política, traço marcante de toda sociedade regida pelo sistema econômico capitalista.

\section{A APLICAÇÃO DO PERCENTUAL MÍNIMO LEGALMENTE VINCULADO À MDE PELOS GOVERNOS DO ESTADO DO RIO DE JANEIRO (1995-2015)}

Atualmente a rede pública estadual do Rio de Janeiro possui 780.253 alunos matriculados na educação básica, segundo dados do Censo do Instituto Nacional de Estudos e Pesquisas Educacionais Anísio Teixeira (Inep) de 2014. Um total de 124.516 professores ativos e inativos na educação básica, segundo relatório da Secretaria de Educação do Estado do Rio de Janeiro (Seeduc) de 2015. Possui ainda 1.374 professores da educação básica contratados. Ainda segundo o Censo do Inep (2014), a Seeduc conta com 1.290 unidades escolares.

O estado do Rio de Janeiro tem o segundo maior PIB do país ( $\mathrm{R}$ 695 bilhões) e respondeu em 2015 por 11,8\% do PIB do país, com renda per capita de R $\$ 41.971$, segundo estimativa da Fundação Centro Estadual de Estatísticas, Pesquisas e Formação de Servidores Públicos do Rio de Janeiro (Ceperj).

No que se refere aos recursos financeiros da educação, segundo o Tribunal de Contas do Estado do Rio de Janeiro (TCE-RJ), em 2015, a arrecadação das receitas que compõem a base de cálculo, para apuração do percentual mínimo em MDE, totalizou R \$ 34.688.843.724,00. O governo estadual afirma ter aplicado $\mathrm{R} \$ \mathbf{9}$ 9.015.498.426,00, o que correspondeu a 25,99\% da receita resultante de impostos na MDE. O impacto das transferências de matrículas para os municípios revela-se na perda de recursos do Fundeb. O governo contribuiu, em 2015, com R\$ 5.710.500.543,00 para o Fundo e recebeu apenas $\mathrm{R} \$ 2.615 .380 .165,00$, uma perda de $\mathrm{R} \$$ 3.095.120.378,00. O total aplicado na Função Educação foi de R \$ 6.183.619.913,00.

Os dados supracitados revelam a dimensão da rede pública estadual, de modo que fica clara a necessidade de analisar a questão dos recursos públicos para a educação básica, sobretudo a vinculação do percentual mínimo de impostos e transferências na MDE, uma vez que esses recursos representam a maior parte do total de recursos aplicados em educação pelo governo estadual.

Para garantir uma educação de qualidade, é necessário ampliar os investimentos na área, conforme assegurou a Constituição do Estado do Rio de Janeiro no artigo 314, que diz: “O Estado aplicará, anualmente, nunca menos de 35\% (trinta e cinco por cento) da receita de impostos, compreendida a proveniente de transferências, na MDE público, incluídos os percentuais referentes 
à UERJ (6\%) e à FAPERJ (2\%)" (RIO DE JANEIRO, 1989). Observe que para a educação básica o percentual seria de apenas $27 \%$, pois $8 \%$ estariam comprometidos com a Universidade do Estado do Rio de Janeiro (UERJ) e a Fundação de Amparo à Pesquisa do Estado do Rio de Janeiro (FAPERJ), que compõem o ensino superior, nível de ensino que não é prioridade para o governo estadual, segundo o art. 211 da CF/88. Contudo, a UERJ já existia antes da promulgação da $\mathrm{CF} / 88$, sendo assim, o governo estadual deve financiá-la. O mais adequado seria que o percentual da FAPERJ fosse contabilizado fora dos 35\%, o que foi inclusive recomendado pelo TCE-RJ em 2010.

Em 1992, o ex-governador Leonel de Moura Brizola, do Partido Democrático Trabalhista (PDT), ajuizou a ADI 780/RJ, no STF, alegando, dentre outras coisas, que aplicar 35\% dos recursos oriundos de impostos e transferências na MDE era inconstitucional, pois engessaria a atividade do Poder Executivo em matéria orçamentária. Em Sessão Plenária de 11 de março de 1993, o STF concedeu parcialmente a medida cautelar pleiteada na ADI. Em 2008, foi julgada prejudicada, por perda de objeto, em razão da renumeração dos artigos questionados pela Emenda Constitucional n. 04, de 1991.

Diante de tal decisão, o governador Sérgio Cabral do Partido do Movimento Democrático Brasileiro (PMDB) propôs a ADI 4102, em 3 de julho de 2008, contestando a constitucionalidade, dentre outros, do artigo 311 da Constituição Estadual, renumerado para 314, tendo sido deferida liminar pelo STF, em 17 de julho de 2008, suspendendo a vigência do dispositivo em questão.

Em discurso proferido no plenário da Assembleia Legislativa do Estado do Rio de Janeiro (Alerj), o deputado estadual e presidente da Comissão Permanente de Educação da Alerj, Comte Bittencourt do Partido Popular Socialista (PPS), explicou que:

Em 1993, o governo do Estado conseguiu efeito suspensivo, através de uma ação direta de inconstitucionalidade, e o Ministro Celso de Melo, em janeiro deste ano, ou seja, 15 anos depois da Adin, conquistada pelo Poder Executivo, o Ministro Celso de Melo, precisamente no dia 31 de janeiro de 2008, julgou prejudicada aquela decisão da Adin de 93; ou seja, no Estado do Rio de Janeiro passou a prevalecer aquele dispositivo, que era o desejo e intenção dos constituintes de 89: a aplicação dos 35\% em educação; e, desses 35\%, $6 \%$ na Uerj. Dia 31 de janeiro, diário oficial eletrônico do Supremo Tribunal Federal. (ALERJ, 2008).

Seis meses após a decisão do STF, o ministro Gilmar Mendes, contrariando a decisão do ministro Celso de Melo, concedeu liminar ao pedido do governo estadual pela inconstitucionalidade dos artigos 308 e 314 da Constituição Estadual e, assim, definiu a aplicação no mínimo de $25 \%$ em MDE na educação estadual do Rio de Janeiro.

Em 2010, o deputado estadual e presidente da Comissão Permanente de Educação da Alerj, Comte Bittencourt, protocolou a Proposta de Emenda à Constituição (PEC) n. 64, alterando o artigo 
314 da Constituição Estadual com a seguinte redação: "O Estado, no prazo máximo de 5 (cinco) anos, passará a aplicar, anualmente, nunca menos de 30\% (trinta por cento) da receita de impostos, compreendida a proveniente de transferências, na MDE público" (ALERJ, 2010). O percentual de $30 \%$ previsto na PEC era menor que o percentual do texto original da Constituição Estadual, de $35 \%$. Com o fim da legislatura, a PEC foi arquivada; ao ser reeleito para o cargo de deputado, Comte Bittencourt solicitou o desarquivamento da PEC.

O STF, em outubro de 2014, decidiu pela inconstitucionalidade do artigo 314 da Constituição Estadual que determinava que o governo deveria destinar, pelo menos, $35 \%$ da receita estadual de impostos à área da educação, sendo $6 \%$ para UERJ.

Em 2015, o líder do governo na Alerj, deputado estadual Edson Albertassi (PMDB), protocolou uma PEC, que prevê a redução do percentual mínimo da receita resultante de impostos e transferências na MDE estadual de $35 \%$ para $25 \%$.

Provavelmente a PEC do deputado Albertassi visa adequar o percentual mínimo com base na decisão do STF e pôr um fim às discussões acerca da aplicação de um percentual maior que o previsto na $\mathrm{CF} / 88$ (25\%) e de fato enterrar qualquer possibilidade legal do governo estadual ter que vir a aplicar o percentual de 35\% na MDE da educação pública estadual e de se comprometer com percentuais para a UERJ e para a FAPERJ, pois a PEC do deputado é omissa em relação a um percentual para essas duas instituições.

A Tabela 2 demonstra os recursos em MDE que poderiam ter sido aplicados pelos governos estaduais desde 1995 caso os governos aplicassem 35\% na MDE. Cabe destacar que o período analisado coincide com o período da pesquisa em tela (1995 a 2015), além disso, a dificuldade de encontrar os dados orçamentários e financeiros de períodos anteriores impôs a restrição da análise nesse período. O TCE-RJ só disponibiliza a Conta de Gestão Pública do Estado no período de 1996 a 2015. No site da Secretaria de Estado de Planejamento e Gestão (Seplag) e da Alerj, também não foi possível encontrar os dados relativos à base de impostos e transferências para MDE.

Tabela 2 - Diferença entre o que os governos estaduais do RJ aplicaram em MDE e o que poderia ter sido aplicado com base no percentual que determina a Constituição Estadual de 1995-2015. Valores reais em (R\$)

\begin{tabular}{|c|c|c|c|c|c|c|c|c|c|}
\hline $\begin{array}{c}\text { Exercício } \\
\text { Financeiro }\end{array}$ & Governos & \multicolumn{2}{|c|}{$\begin{array}{l}\text { Receita para base do } \\
\text { cálculo em MDE }\end{array}$} & \multicolumn{2}{|c|}{ Aplicado pelo $\mathbf{R J}=(\mathbf{A})$} & \multicolumn{2}{|r|}{$35 \%=(B)$} & \multicolumn{2}{|r|}{$A-B=C$} \\
\hline 1995 & $\begin{array}{l}\text { Alencar } \\
\text { (PSDB) }\end{array}$ & $\mathrm{R} \$$ & $20.478 .613 .475,09$ & $\mathrm{R} \$$ & $7.288 .338 .535,78$ & $\mathrm{R} \$$ & 7.167.514.716,28 & $\mathrm{R} \$$ & $120.823 .819,50$ \\
\hline 1996 & & $\mathrm{R} \$$ & $21.187 .806 .891,92$ & $\mathrm{R} \$$ & $7.854 .320 .014,83$ & $\mathrm{R} \$$ & 7.415.732.412,17 & $\mathrm{R} \$$ & $438.587 .602,66$ \\
\hline 1997 & & $\mathrm{R} \$$ & $19.675 .368 .376,65$ & $\mathrm{R} \$$ & 7.293.659.057,22 & $\mathrm{R} \$$ & $6.886 .378 .931,83$ & $\mathrm{R} \$$ & $407.280 .125,40$ \\
\hline 1998 & & $\mathrm{R} \$$ & $24.679 .497 .492,44$ & $\mathrm{R} \$$ & $7.041 .060 .634,59$ & $\mathrm{R} \$$ & $8.637 .824 .122,35$ & $-\mathrm{R} \$$ & $1.596 .763 .487,76$ \\
\hline
\end{tabular}




\begin{tabular}{|c|c|c|c|c|c|c|c|c|c|}
\hline 1999 & $\begin{array}{c}\text { Anthony } \\
\text { Garotinho } \\
\text { (PDT-PSB) } \\
\text { Benedita da } \\
\text { Silva } \\
\text { (PT) }\end{array}$ & $\mathrm{R} \$$ & $22.550 .948 .781,15$ & $\mathrm{R} \$$ & $6.884 .804 .662,89$ & $\mathrm{R} \$$ & $7.892 .832 .073,40$ & $-\mathrm{R} \$$ & $1.008 .027 .410,52$ \\
\hline 2000 & & $\mathrm{R} \$$ & 23.038.994.574,14 & $\mathrm{R} \$$ & $6.040 .824 .377,34$ & $\mathrm{R} \$$ & $8.063 .648 .100,95$ & $-\mathrm{R} \$$ & $2.022 .823 .723,61$ \\
\hline 2001 & & $\mathrm{R} \$$ & $24.088 .111 .759,04$ & $\mathrm{R} \$$ & $6.433 .934 .650,84$ & $\mathrm{R} \$$ & $8.430 .839 .115,66$ & $-\mathrm{R} \$$ & $1.996 .904 .464,82$ \\
\hline 2002 & & $\mathrm{R} \$$ & $22.398 .761 .741,29$ & $\mathrm{R} \$$ & $5.859 .516 .071,52$ & $\mathrm{R} \$$ & $7.839 .566 .609,45$ & $-\mathrm{R} \$$ & $1.980 .050 .537,93$ \\
\hline 2003 & $\begin{array}{c}\text { Rosinha } \\
\text { Garotinho } \\
\text { (PSB-PMDB) }\end{array}$ & $\mathrm{R} \$$ & $24.157 .143 .132,19$ & $\mathrm{R} \$$ & $6.986 .245 .793,83$ & $\mathrm{R} \$$ & $8.455 .000 .096,27$ & $-\mathrm{R} \$$ & $1.468 .754 .302,44$ \\
\hline 2004 & & $\mathrm{R} \$$ & $25.170 .515 .538,85$ & $\mathrm{R} \$$ & $6.589 .640 .968,07$ & $\mathrm{R} \$$ & $8.809 .680 .438,60$ & $-\mathrm{R} \$$ & $2.220 .039 .470,53$ \\
\hline 2005 & & $\mathrm{R} \$$ & $25.667 .353 .615,14$ & $\mathrm{R} \$$ & $6.663 .244 .998,49$ & $\mathrm{R} \$$ & $8.983 .573 .765,30$ & $-\mathrm{R} \$$ & $2.320 .328 .766,81$ \\
\hline 2006 & & $\mathrm{R} \$$ & $27.444 .219 .344,32$ & $\mathrm{R} \$$ & $6.888 .499 .055,42$ & $\mathrm{R} \$$ & $9.605 .476 .770,51$ & $-\mathrm{R} \$$ & 2.716.977.715,09 \\
\hline 2007 & $\begin{array}{c}\text { Sérgio Cabral } \\
\text { (PMDB) }\end{array}$ & $\mathrm{R} \$$ & $27.622 .987 .834,51$ & $\mathrm{R} \$$ & $6.916 .796 .153,76$ & $\mathrm{R} \$$ & $9.668 .045 .742,08$ & $-\mathrm{R} \$$ & $2.751 .249 .588,32$ \\
\hline 2008 & & $\mathrm{R} \$$ & $28.183 .486 .626,71$ & $\mathrm{R} \$$ & $7.071 .236 .794,64$ & $\mathrm{R} \$$ & $9.864 .220 .319,35$ & $-\mathrm{R} \$$ & $2.792 .983 .524,71$ \\
\hline 2009 & & $\mathrm{R} \$$ & $30.501 .898 .466,59$ & $\mathrm{R} \$$ & 7.634.625.186,19 & $\mathrm{R} \$$ & $10.675 .664 .463,31$ & $-\mathrm{R} \$$ & $3.041 .039 .277,12$ \\
\hline 2010 & & $\mathrm{R} \$$ & $32.627 .937 .937,65$ & $\mathrm{R} \$$ & $8.212 .451 .978,91$ & $\mathrm{R} \$$ & $11.419 .778 .278,18$ & $-\mathrm{R} \$$ & $3.207 .326 .299,27$ \\
\hline 2011 & $\begin{array}{c}\text { Sérgio Cabral } \\
\text { (PMDB) } \\
\text { Luiz Fernando } \\
\text { Pezão } \\
\text { (PMDB) }\end{array}$ & $\mathrm{R} \$$ & $34.096 .382 .653,73$ & $\mathrm{R} \$$ & 8.558.192.046,09 & $\mathrm{R} \$$ & $11.933 .733 .928,81$ & $-\mathrm{R} \$$ & $3.375 .541 .882,72$ \\
\hline 2012 & & $\mathrm{R} \$$ & $34.458 .190 .664,15$ & $\mathrm{R} \$$ & $8.655 .897 .494,83$ & $\mathrm{R} \$$ & $12.060 .366 .732,45$ & $-\mathrm{R} \$$ & $3.404 .469 .237,62$ \\
\hline 2013 & & $\mathrm{R} \$$ & $37.584 .107 .168,17$ & $\mathrm{R} \$$ & $9.572 .672 .095,73$ & $\mathrm{R} \$$ & $13.154 .437 .508,86$ & $-\mathrm{R} \$$ & $3.581 .765 .413,13$ \\
\hline 2014 & & $\mathrm{R} \$$ & $37.637 .042 .087,07$ & $\mathrm{R} \$$ & $9.635 .082 .774,29$ & $\mathrm{R} \$$ & $13.172 .964 .730,47$ & $-\mathrm{R} \$$ & $3.537 .881 .956,18$ \\
\hline 2015 & $\begin{array}{c}\text { Luiz Fernando } \\
\text { Pezão } \\
\text { (PMDB) }\end{array}$ & $\mathrm{R} \$$ & $34.688 .843 .724,00$ & $\mathrm{R} \$$ & $9.015 .498 .426,00$ & $\mathrm{R} \$$ & $12.141 .095 .303,40$ & $-\mathrm{R} \$$ & $3.125 .596 .877,40$ \\
\hline TOTAL & & $\mathbf{R} \$$ & 577.938.211.884,80 & $\mathbf{R} \$$ & 157.096.541.771,28 & $\mathbf{R} \$$ & 202.278.374.159,68 & $-\mathbf{R} \$$ & 45.181.832.388,40 \\
\hline
\end{tabular}

Fonte: TCE-RJ, SIOPE e Seeduc. Tabela elaborada pelo autor.

Os dados auferidos satisfazem a análise sobre o montante que o estado deixou de aplicar em MDE durante os últimos vinte um exercícios financeiros em seis governos: Marcello Alencar, Anthony Garotinho e Benedita da Silva, Rosinha Garotinho, Sérgio Cabral, Sérgio Cabral e Luiz Fernando Pezão e Luiz Fernando Pezão.

Os valores do Gráfico 1 foram retirados da fonte supramencionada e corrigidos para valores reais pelo Índice Geral de Preços (IGP-DI) da Fundação Getúlio Vargas (FGV) tendo como base o mês de dezembro de 2015. Esse índice mede o comportamento de preços em geral da economia brasileira.

Com base na Tabela 2 foi construído o Gráfico 1, que demonstra visualmente a diferença entre o que o governo estadual aplicou durante os últimos 21 exercícios financeiros seguindo a interpretação do percentual que poderia ter sido aplicado, no mínimo, na MDE. 
Gráfico 1 - Aplicação de impostos e transferências na MDE pelos governos estaduais e pela Constituição estadual de 1989 (1995 a 2015). Valores reais em (R\$)

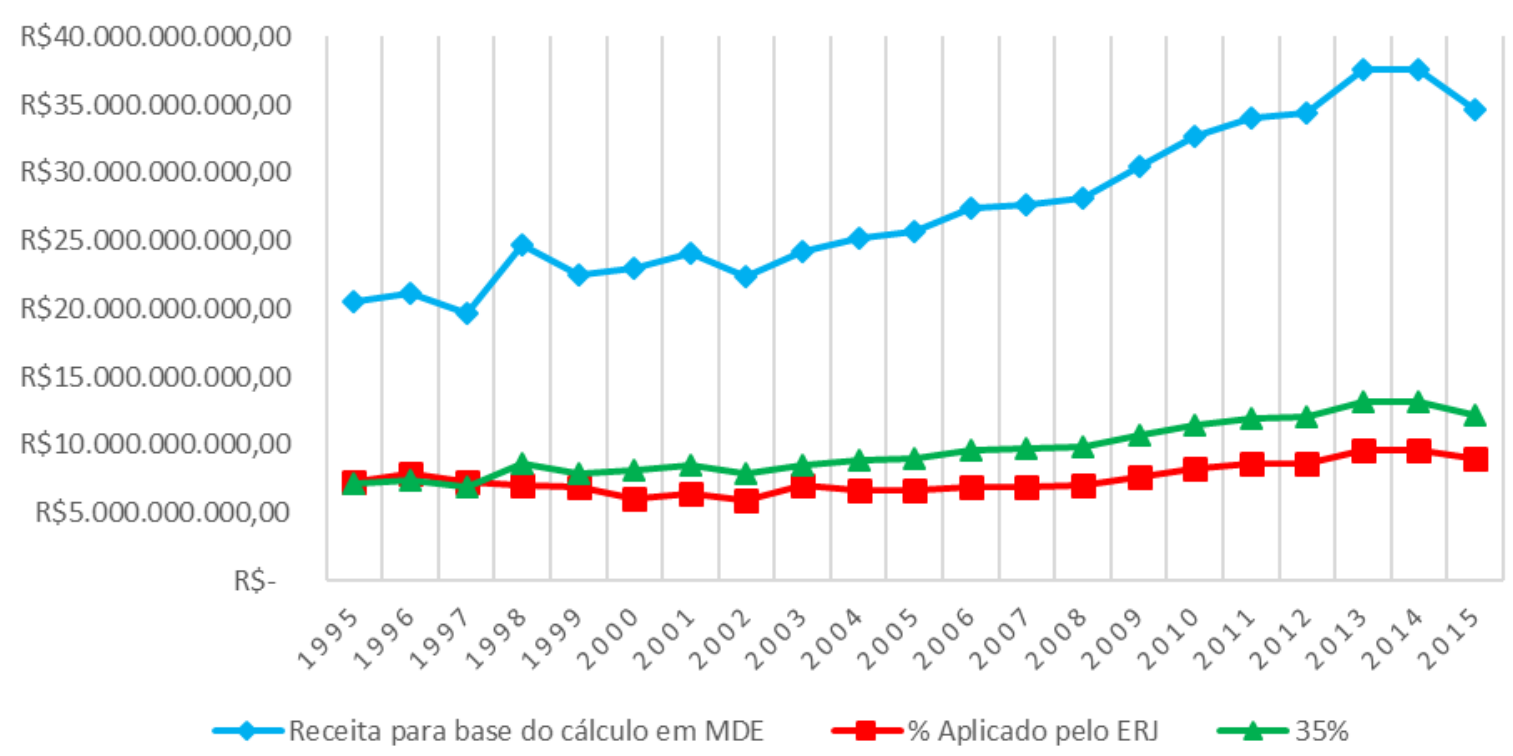

Fonte: TCE-RJ, SIOPE e Seeduc. Gráfico elaborado pelo autor.

A Tabela 2 e o Gráfico 1 assinalam que houve um crescimento anual da receita resultante de impostos e transferência legais e constitucionais que forma a base de cálculo do percentual de recursos a serem aplicados na MDE da Educação Básica. Houve aumento, portanto, na receita de recursos aplicados pelo governo estadual em MDE. De 1995 e 1996, o governo contabilizou os recursos do Salário-Educação na MDE; em 1998, contabilizou recursos municipais do Fundef (uma diferença de mais de R \$ 694 milhões). Essas irregularidades apontadas pelo TCE-RJ interferem na análise do gráfico. Por exemplo, nos exercícios financeiros de 1995, 1996 e 1997, o gráfico aponta que houve a aplicação de mais de $35 \%$ da receita resultante de impostos e transferências constitucionais; contudo, há a contabilização de despesas que não condizem com MDE nesses exercícios, conforme apontado anteriormente, e isso possivelmente diminuiria o percentual que o governo diz ter aplicado.

A importância desse gráfico está na receita potencial que o governo estadual deixou e ainda deixa de aplicar em MDE por não ter considerado constitucional o artigo da Constituição Estadual, que determina, no mínimo, 35\% da receita resultante de impostos e transferências em MDE. De 1995 até 2015, em valores reais e corrigidos, um montante de mais de $\mathrm{R} \$ 45$ bilhões poderia ter sido aplicado em MDE. Esse valor é resultado do cálculo de $35 \%$ da receita de impostos e 
transferências que serve de base para o cálculo do percentual, subtraído do valor aplicado pelo governo estadual durante o período analisado.

É importante ressaltar que a atual crise da UERJ diante dos poucos recursos vinculados tem acarretado efeitos negativos para a instituição, uma vez que parte dos compromissos financeiros não tem sido cumprida. Pode-se notar que, ao não levar em consideração o percentual de $6 \%$ para o financiamento da Universidade, os governos estaduais e o STF colaboraram para a atual crise da instituição que tem cogitado até a possibilidade de fechamento.

Embora, em 2014, a decisão do STF tenha mantido o percentual de $2 \%$ para a FAPERJ, o governo estadual, em 2016, enviou à ALERJ a PEC n. 19 que prevê a redução à metade, até 31 de dezembro de 2018, desse percentual.

Além disso, o descompromisso do governo estadual com a educação pública de qualidade se revela, também, no atraso para aprovar o Plano Estadual de Educação (PEE-RJ). Segundo a Lei 13.005 de 2014, que aprovou o Plano Nacional de Educação (PNE), art. 8º estados, Distrito Federal e municípios deveriam, no prazo de um ano, elaborar ou adequar seus Planos em consonância com as diretrizes, metas e estratégias previstas no PNE. Porém, até a presente data, o PEE-RJ não foi aprovado, o que denota o descompromisso do governo estadual, que foi, inclusive, apontado pelo próprio TCE-RJ no relatório de prestação de contas do governo em 2015:

(...) o Plano Estadual de Educação, que deveria ter sido elaborado ou adequado até 25.06.15, por força do prazo disposto no art. $8^{\circ}$ da Lei Federal $n^{\circ} 13.005$, de 25 de junho de 2014, ainda não teve sua lei aprovada, sendo o Estado do Rio de Janeiro o único da Federação que não possui sequer o projeto de lei elaborado. (TCE-RJ, 2015, p.56)

Com base em uma pesquisa realizada acerca da meta referente ao financiamento da educação nos Planos Estaduais de Educação, os estados do Rio de Janeiro e de Minas Gerais (que ocupam o segundo e o terceiro PIBs do país, respectivamente) não tiveram a Lei do Plano sancionada no prazo determinado pela Lei n. 13.005/2014. Para Souza (2016, p.260), “(...) a desarticulação e a demora para aprovarem seus Planos, no prazo definido pelo MEC, denota uma irresponsabilidade de seus governantes".

A versão preliminar do PEE-RJ lançado pela Seeduc, em 2015, traz como meta para o financiamento da educação a ampliação do investimento público em educação pública de forma a atingir, no mínimo, o patamar de 7\% do PIB do Estado no quinto ano de vigência do Plano e, no mínimo, o equivalente a $10 \%$ do PIB ao final do decênio (RIO DE JANEIRO, 2016). Contudo, analisando as 16 estratégias, que deveriam estar alinhadas com a meta do próprio PEE e do PNE, 
não foi possível constatar o esforço do governo estadual em ampliar os recursos do governo, para garantir o cumprimento da meta, em nenhuma das estratégias. Cabe destacar que se trata de uma minuta e que, portanto, será submetida a outras instâncias para debate e alterações; porém, revela muito em relação ao comprometimento do governo estadual em construir uma meta para o financiamento da educação estadual com estratégias inócuas do ponto de vista da ampliação dos recursos para a educação.

\section{CONCLUSÃO}

Esta pesquisa demonstrou o descompromisso de alguns governos estaduais, em especial do Rio de Janeiro, ao não levarem em consideração o percentual mínimo previsto na Constituição Estadual, sob o pretexto de que este fere a $\mathrm{CF} / 88$ no que se refere à exclusividade do Poder Executivo em legislar sobre matéria orçamentária. Além disso, cabe destacar que tanto a CF/88 como a Constituição Estadual tratam de um percentual mínimo e não de um teto para aplicar na MDE, além disso, os(as) governadores (as), desde 1998, vêm utilizando o percentual mínimo menor, ou seja, o previsto pela CF/88 quando o percentual de sua Constituição e acima deste.

Isso denota o descompromisso de alguns governos com a educação pública estadual, pois um aporte maior de recursos seria capaz de melhorar a qualidade da rede estadual e de valorizar os profissionais da educação, caso a destinação da aplicação desses recursos chegassem a sua finalidade. As assimetrias regionais e locais, no que se refere aos orçamentos entre os governos estaduais, são profundas. É inadmissível que o estado do Rio de Janeiro que possui o segundo maior PIB do país seja o único, dentre os cinco estados com os maiores PIBs, que aplique algo em torno do percentual mínimo previsto na $\mathrm{CF} / 88$ para MDE mesmo estando previsto em sua Constituição um percentual maior que o da $\mathrm{CF} / 88$.

O STF, em 2014, decidiu através de um acórdão que o artigo 314 que previa a aplicação de, no mínimo, 35\% na MDE era inconstitucional, pois considerou que essa permanente destinação de dotação preestabelecida era um prejuízo para o julgamento do governador sobre as prioridades do seu governo, ou seja, o piso estabelecido pela Constituição Estadual limitava a liberdade constitucional do governador de priorizar outras áreas que considerasse mais importante ao elaborar a legislação orçamentária.

Diante da necessidade de se aplicar mais recursos na MDE, sobretudo o governo do estado do Rio de Janeiro que dispõe de um orçamento bilionário, seria importante de forma democrática priorizar as demandas da rede estadual e construir um PEE-RJ que traduza essas prioridades, que, 
com certeza, apontariam para o aumento de recursos cuja fonte poderia ser da receita resultante de impostos na MDE, baseada no percentual que estava previsto na sua Constituição Estadual antes da decisão do STF.

\section{BIBLIOGRAFIA}

BRASIL. Constituição da República Federativa do Brasil de 1988. Brasília: Senado Federal. Disponível em: <www.senado.gov.br>. Acesso em: 20 nov. 2016.

BRASIL. Constituições do Brasil (de 1824, 1891, 1934, 1937, 1946 e 1967 e suas alterações). Brasília: Senado Federal, Subsecretaria de Edições Técnicas, 1986.

MEC. INEP. Censo Escolar de 2014. Disponível em: <www.inep.gov.br>. Acesso em: 20 nov. 2016.

CALLEGARI, Cesar. A luta contra a sonegação de recursos do ensino público no Estado de São Paulo. As verbas da educação. São Paulo: Entrelinhas, 1997.

CASTRO, Jorge Abrahão de. Financiamento da Educação Pública no Brasil: Evolução dos Gastos. In: UNESCO. Educação e federalismo no Brasil: combater as desigualdades, garantir a diversidade. Brasília, 2010. p. 169-190.

DAVIES, Nicholas. O financiamento da educação e seus desafios. EccoS Revista Científica, UNINOVE, São Paulo, v. 6, n. 1, 2004.

DAVIES, Nicholas. O Compromisso Educacional da União, Estados e Municípios: colaboração, subordinação ou omissão? Germinal: Marxismo e Educação em Debate, v. 8, n. 1, p. 116-125, 2016.

DOURADO, Luiz Fernandes. Sistema Nacional de Educação, Federalismo e os obstáculos ao direito à educação básica. Educação \& Sociedade, v. 34, n. 124, p. 761-785, 2013.

RIO DE JANEIRO (Estado). Versão Preliminar Plano Estadual De Educação do Estado do Rio de Janeiro 2015 2024. Disponível em: <http://download.rj.gov.br/ documentos/10112/2298861/DLFE-76202.pdf/MINUTAPLANO ESTADUAL2014MARCO2015.pdf>. Acesso em: 29 nov. 2016.

Assembleia Legislativa do Estado do Rio de Janeiro. Constituição Estadual do Estado do Rio de Janeiro. Disponível em: <http://alerjln1.alerj.rj.gov.br/constest. nsf/PageConsEst?OpenPage〉. Acesso em: 15 nov. de 2016.

Assembleia Legislativa do Estado do Rio de Janeiro. Notas Taquigráficas do discurso - Comte Bittencourt, 7 ago. 2008. Disponível em:<http://alerjln1.alerj.rj. gov. br/taqalerj2006.nsf/8b99ca38e 07826db032565300046fdf1 /901ceb90ac947a6183257b6b0065a356?OpenDocument\&ExpandSection=1\#_Section1>. Acesso em: 24 fev. 2016.

SOUZA, Fábio Araujo de. Os Planos Estaduais de Educação: uma análise acerca da meta referente ao financiamento da educação. Movimento-revista de educação, Niterói, 252-283, n. 5, 2016.

TCE-RJ. Tribunal de Contas do Estado do Rio de Janeiro. Contas de Gestão do Governador - Exercícios (1996,1998, 1999, 2000, 2001, 2002, 2003, 2004, 2005, 2006, 2007, 2008, 2009, 2010, 2011, 2012, 2013, 2014 e 2015). TCE, Rio de Janeiro. Disponível em: <http://www.tce.rj.gov.br>. Acesso em: 29 nov. 2016.

TRAVINCAS, Amanda Costa Thomé. Vinculação de receita mínima para a satisfação do direito à educação no Brasil (CF, Art. 212) dirigismo constitucional e dever de progressividade. Justiça \& Sociedade-Revista do Curso de Direito do IPA, n. 1, p. 67-100, 2016.

VELloso, Jaques. A emenda Calmon e os recursos da União. Cadernos Pesquisa, São Paulo: Fundação Carlos Chagas, 1990. 


\section{RESUMO}

Este estudo tem por objetivo analisar a aplicação do percentual mínimo de recursos para Manutenção e Desenvolvimento do Ensino (MDE) pelos governos do estado do Rio de Janeiro de 1995 a 2015. A Constituição Estadual (1989) previa a aplicação de, no mínimo, 35\% da receita resultante de impostos para MDE, contudo, em 1993, o Supremo Tribunal Federal (STF) concedeu liminar ao governador permitindo a aplicação do percentual mínimo previsto na CF/1988, que é de $25 \%$, ou seja, $10 \%$ menor que o previsto na Constituição Estadual. Em 2014, a decisão do STF considerou inconstitucional o percentual mínimo previsto na Constituição Estadual. A pesquisa concluiu que com essas medidas a educação fluminense deixou de aplicar mais de R\$ 45 bilhões na MDE estadual no período pesquisado.

Palavras-chave: Vinculação constitucional. Constituição Estadual. Governos estaduais do Rio de Janeiro.

\section{ABSTRACT}

This study aims to analyze the application of the minimum percentage of resources to the Maintenance and Development of Education (MDE) by the government of the state of Rio de Janeiro from 1995 to 2015 . The State Constitution (1989) foresaw the application of, at least, $35 \%$ of the revenue resulting from taxes to the MDE, however, in 1993, the Federal Supreme Court (STF) granted an injunction to the governor allowing the application of the minimum percentage provided for in CF/1988, which is $25 \%$, or $10 \%$ smaller than provided for in the State Constitution. In 2014, the decision of the STF court held unconstitutional the minimum percentage provided in the State Constitution. The research has concluded that with these measures the education fluminense no longer apply more than R 45 billion in MDE state in the researched period.

Keywords: Binding constitutional. The Constitution Of The State. State governments of Rio de Janeiro.

\section{RESUMEN}

Este estudio tiene por objetivo analizar la aplicación del porcentaje mínimo de recursos para el Mantenimiento y El desarrollo de la Educación (MDE) de los gobiernos del estado de Río de Janeiro de 1995 a 2015. La La constitución del estado (1989) preveía la aplicación de, al menos, el 35\% de los ingresos resultante de impuestos para MDE, sin embargo, en 1993, el Supremo Tribunal Federal (STF), concedió la medida cautelar al gobernador permitiendo la aplicación del porcentaje mínimo previsto en la CF/1988, que es de 25\%, o sea, un $10 \%$ menor que el previsto en la La Constitución Del Estado. En 2014, la decisión de la corte suprema consideró inconstitucional el porcentaje mínimo previsto en la La Constitución Del Estado. La investigación concluyó que con estas medidas la educación fluminense dejó de aplicar más de\$ 45 mil millones en MDE estatal en el periodo investigado.

Palabras clave: Vinculación constitucional. La Constitución Del Estado. Los gobiernos estatales de Río de Janeiro. 